\title{
Inhibition of mTOR promotes hyperthermia sensitivity in SMMC-7721 human hepatocellular carcinoma cell line
}

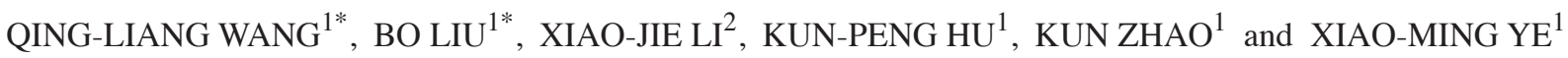 \\ Departments of ${ }^{1}$ General Surgery and ${ }^{2}$ Laboratory Medicine, Ling Nan Hospital, \\ The Third Affiliated Hospital of Sun Yat-Sen University, Guangzhou, Guangdong 510530, P.R. China
}

Received June 27, 2015; Accepted December 2, 2015

DOI: $10.3892 /$ etm.2016.2979

\begin{abstract}
The mammalian target of rapamycin (mTOR) is a critical mediator of the phosphoinositide 3-kinase/protein kinase B/mTOR signaling pathway, and mTOR activity is induced following heat shock. Thermotherapy is used to treat hepatocellular carcinoma (HCC). However, the role of mTOR in modulating thermosensitivity in $\mathrm{HCC}$ has yet to be elucidated. In the present study, the antisense plasmid pEGFP-C1-mTOR was transfected into SMMC-7721 cells, and the expression levels of mTOR were analyzed by reverse transcription-polymerase chain reaction and western blot analysis. The thermal responses of the transfected cells were also examined. The results revealed that SMMC-7721 cells were sensitive to heat treatment, and cell viability was significantly inhibited following hyperthermia treatment $(\mathrm{P}<0.01)$. The mRNA and protein expression levels of mTOR decreased post-transfection. Cell proliferation, colony-forming ability and motility were all significantly decreased following hyperthermia treatment in the transfected cells. Flow cytometry analysis demonstrated that apoptosis was significantly increased following treatment $(\mathrm{P}<0.01)$. The number of cells in $\mathrm{S}$ phase was increased, and the cell cycle was arrested in $\mathrm{S}$ phase. In conclusion, inhibition of mTOR increased the thermosensitivity of SMMC-7721 cells by increasing cellular apoptosis and inducing $\mathrm{S}$ phase arrest.
\end{abstract}

\section{Introduction}

With a rising incidence in recent years, hepatocellular carcinoma (HCC) is now the fifth most common malignancy worldwide (1). More importantly, HCC has a poor prognosis

Correspondence to: Dr Xiao-Ming Ye, Department of General Surgery, Ling Nan Hospital, The Third Affiliated Hospital of Sun Yat-Sen University, 2693 Kai Chuang Avenue, Luogang, Guangzhou, Guangdong 510530, P.R. China

E-mail: james007y@sina.cn

*Contributed equally

Key words: hyperthermia sensitivity, mammalian target of rapamycin, hepatocellular carcinoma, gene expression, apoptosis due to its high rate of recurrence and a lack of effective therapies (2). Hyperthermia is used as a cancer treatment strategy and has few side-effects. It is a therapeutic procedure that raises the body or local temperature $>37^{\circ} \mathrm{C}$ and the usual temperature ranges from $40-43^{\circ} \mathrm{C}$ (3). To date, improvements in thermometry, heat-application technologies and control systems have made hyperthermia a safer and more efficient treatment strategy (4). Experimental and clinical studies on the application of hyperthermia support its therapeutic potential for the treatment of HCC (5).

Local, regional and whole-body hyperthermia treatments have been used in the clinic and yield variable results (6). A variety of techniques such as radiotherapy, microwaves and lasers have gained popularity for the treatment of HCC and have benefited patients who exhibited improved local control and survival (7). However, local recurrence remains an issue following hyperthermia treatment, with local recurrence rates of 1.8-34\% depending on the location and size of the tumor (8). Phenotypic changes in cells following hyperthermia treatment may indicate a resistance to cancer thermotherapy and result in the treatment failure or a high recurrence rate, a process known as thermotolerance (9). Therefore, more efficient strategies to sensitize tumor cells to heat are required.

Heat shock proteins (HSPs) are well-known mediators in response to thermal stress. Although HSPs are the predominantly activated genes following heat shock, it has become apparent that thermal stress also leads to the induction of a substantial number of genes not traditionally considered to be HSPs $(10,11)$. Another major cellular response to thermal stress is the activation of the phosphoinositide 3-kinase $(\mathrm{PI} 3 \mathrm{~K}) /$ protein kinase $\mathrm{B}(\mathrm{Akt}) /$ mammalian target of rapamycin (mTOR) signaling pathway (12). As it serves as a central point in numerous cellular signaling cascades, mTOR has an important role in oncogenesis, DNA repair, tumor growth, angiogenesis and migration (13). Tumor relapse following thermotherapy is caused by thermal tolerance in the residual tumor cells, which decreases the therapeutic effect of heat. However, the activity of mTOR is induced following exposure to hyperthermia (14). Therefore, it was hypothesized for the purposes of the present study that mTOR may be a modulator for thermosensitivity. The present study examined whether inhibition of mTOR affected cellular responses to hyperthermia in SMMC-7721 human HCC cells. 


\section{Materials and methods}

Cell culture and hyperthermia treatment. The SMMC-7721 human HCC cell line was obtained from the Shanghai Institute of Cell Biology at the Chinese Academy of Science (Shanghai, China). The present study was approved by the Ethics committee of the Third Affiliated Hospital of Sun Yat-Sen University (Guangzhou, China). The cells were cultured in Dulbecco's modified Eagle's medium (DMEM) supplemented with $10 \%$ heat-inactivated fetal bovine serum (FBS; Gibco; Thermo Scientific Inc., Waltham, MA, USA). Cell cultures were incubated at $37^{\circ} \mathrm{C}$ in a humidified atmosphere containing $5 \% \mathrm{CO}_{2}$. When the cells covered $70-80 \%$ of the bottle bottom, they were digested using $0.25 \%$ trypsin (Gibco). The cells in the logarithmic phase of growth were used for the following experiments. For hyperthermia treatment, the cells were subjected to heat shock in an incubator (Forma Series II 3110; Thermo Fisher Scientific, Inc.) preheated to 40,42 or $44^{\circ} \mathrm{C}$ for $1 \mathrm{~h}$. A control group was maintained at $37^{\circ} \mathrm{C}$. The temperature was monitored and maintained within $0.1^{\circ} \mathrm{C}$ during the treatment period. Following heat shock treatment, the cells were then re-incubated at $37^{\circ} \mathrm{C}$ for the indicated time periods.

Detection of cell viability. Cells were seeded at an initial density of $1 \times 10^{3}$ cells/well in 96-well plates. Following $24 \mathrm{~h}$ culture at $37^{\circ} \mathrm{C}$ in a humidified atmosphere containing $5 \%$ $\mathrm{CO}_{2}$, the cells were exposed to hyperthermic conditions (40, 42 or $44^{\circ} \mathrm{C}$ ) separately for $1 \mathrm{~h}$ and recovered to $37^{\circ} \mathrm{C}$. After a further $24 \mathrm{~h}$, cell morphology was observed using an inverted microscope (TE2000-U; Nikon Corporation, Tokyo, Japan) and cell viability was measured using a Cell Counting kit-8 (CCK-8; Dojindo Molecular Technologies, Inc., Kumamoto, Japan) according to the manufacturer's protocol. For cells exposed to $42^{\circ} \mathrm{C}$, cell viability was additionally detected at 12, 24, 48, 72 and $96 \mathrm{~h}$ following hyperthermia. The optical absorbance at a wave length of $450 \mathrm{~nm}$ was measured using a microplate reader (Model 680; Bio-Rad Laboratories, Inc., Hercules, CA, USA). The percentage of growth inhibition was calculated using the following formula: 1 - (Absorbance hyperthermia/absorbance at $37^{\circ} \mathrm{C}$ ) x $100 \%$. The growth curves were constructed using average absorbance at $450 \mathrm{~nm}$ (optical density [OD], $450 \mathrm{~nm}$ ) from three independent experiments.

Plasmid and transient transfection. The antisense plasmid pEGFP-C1-mTOR was donated by Dr Yu Guo (Liver Transplant Center, The Third Affiliated Hospital of Sun Yat-Sen University). Transient transfection was conducted using Lipofectamine ${ }^{\circledR} 2000$ reagent (Invitrogen; Thermo Fisher Scientific, Inc.) according to the manufacturer's protocol. SMMC-7721 cells were seeded in 24-well plates $\left(5 \times 10^{4}\right.$ cells/well) one day prior to transfection until they reached $80 \%$ confluence. A total of $1 \mu \mathrm{g}$ plasmid DNA and $3 \mu 1$ transfection reagent were used to transfect the cells in each well in the absence of serum. After $4 \mathrm{~h}$, the medium was replaced with DMEM supplemented with $10 \%$ FBS. The expression of green fluorescent protein was observed using the TE2000-U inverted fluorescence microscope.

Detection of mTOR mRNA expression using reverse transcription-polymerase chain reaction ( $R T-P C R)$.
SMMC-7721 cells were seeded in 6-well plates $\left(1 \times 10^{5}\right.$ cells/well), and cells were collected $36 \mathrm{~h}$ post-transfection. Total RNA was isolated using TRIzol ${ }^{\circledR}$ reagent (Invitrogen; Thermo Fisher Scientific, Inc.) according to the manufacturer's protocol. RNA was reverse transcribed and amplified using a one-step RT-PCR kit (Beijing TransGen Biotech Co., Ltd., Beijing, China). Genomic DNA was removed using phenol/chloroform extraction. Next, $1 \mu \mathrm{g}$ isolated RNA was included in a $20-\mu \mathrm{l}$ reaction mixture together with $0.5 \mu$ l Forward Primer, $0.5 \mu 1$ Reverse Primer, $12 \mu 1$ 2X One-Step Reaction Mix and $0.5 \mu 1$ EasyScript One-Step Enzyme Mix. RNA was reverse transcribed and amplified using an ABI 2700 Real-Time PCR System (Applied Biosystems; Thermo Fisher Scientific, Inc., Foster City, CA, USA). The reaction was performed under the following conditions: $94^{\circ} \mathrm{C}$ for $12 \mathrm{~min}$, and then 30 cycles $94^{\circ} \mathrm{C}$ for $30 \mathrm{sec}, 54^{\circ} \mathrm{C}$ for $30 \mathrm{sec}$ and $72^{\circ} \mathrm{C}$ for $30 \mathrm{sec}$ followed by a final extension at $72^{\circ} \mathrm{C}$ for $5 \mathrm{~min}$. The mRNA expression levels of mTOR were measured using the following gene-specific primers: mTOR forward, 5'-CGCTGTCATCCCTTTATCG-3' and reverse, 5'-ATGCTCAAACACCTCCACC-3'. The relative mRNA expression levels of mTOR were normalized against those of $\beta$-actin using the following gene-specific primers: $\beta$-actin forward, 5'-GGACTTCGAGCAAGAGATGG-3', and reverse, 5'-AGCACTGTGTTGGCGTACAG-3'. The primers were synthesized by Shanghai Sangon Biological Engineering Technology and Services Co., Ltd. (Shanghai, China). The amplified PCR products were subjected to electrophoresis in $1 \%$ agarose gel (Sangon Biotech Co. Ltd., Shanghai, China), then stained with ethidium bromide (Sigma-Aldrich, St. Louis, MO, USA). All experiments were repeated at least three times. The photo-density ratio of the RT-PCR product for mTOR and $\beta$-actin was used to identify the expression levels of the target gene. The optical density of each sample band was captured using a UV gel imaging system (GDS-8000; Ultra-Violet Products Ltd., Cambridge, UK) and analyzed using Quantity One Image software (Bio-Rad Laboratories, Inc.). The density ratio of the RT-PCR product for $\mathrm{mTOR}$ and $\beta$-actin was used to identify the expression levels of the target gene.

Western blot analysis. Post-transfection, cells were harvested, washed twice in ice-cold phosphate-buffered saline (PBS; Wuhan Boster Biological Technology Ltd., Wuhan, China) and then lysed on ice for $30 \mathrm{~min}$ in RIPA lysis buffer containing $1 \mathrm{mM}$ phenylmethylsulfonyl fluoride (Beyotime Institute of Biotechnology, Shanghai, China). After centrifugation at $10,000 \mathrm{x} \mathrm{g}$ for $5 \mathrm{~min}$, the supernatant was harvested to obtain the total cellular protein extract. The protein concentrations were assessed using a bicinchoninic acid protein assay kit (Beijing Comwin Biotech Co., Ltd., Beijing, China). After the protein concentrations were assessed, $50 \mu \mathrm{g}$ total protein was separated using 10\% SDS-PAGE (Beyotime Institute of Biotechnology) and transferred onto nitrocellulose membranes (Beijing Comwin Biotech Co., Ltd.). Following blocking in $5 \%$ non-fat dry milk in $25 \mathrm{mM}$ Tris-buffered saline $(150 \mathrm{mM} \mathrm{NaCl})$ with $0.1 \%$ Tween 20 buffer (Shanghai Sangon Biological Engineering Technology and Services Co., Ltd., Shanghai, China), the membranes were incubated with rabbit anti-human mTOR primary antibody (1:400; sc-8319) overnight at $4^{\circ} \mathrm{C}$, then with secondary horseradish peroxidase-conjugated goat anti-rabbit immunoglobulin G (1:5,000; 
A

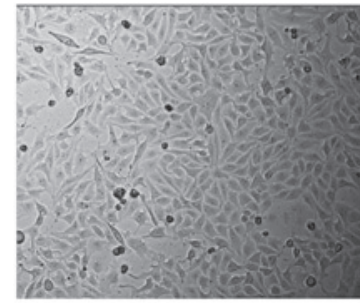

$37^{\circ} \mathrm{C}$

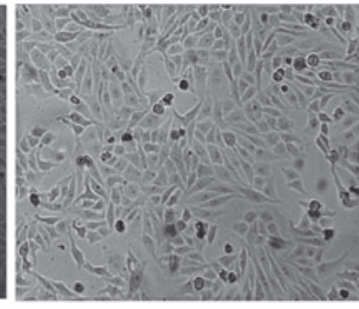

$40^{\circ} \mathrm{C}$

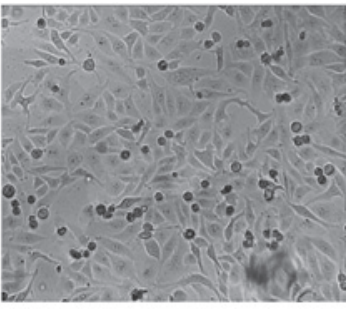

$42^{\circ} \mathrm{C}$

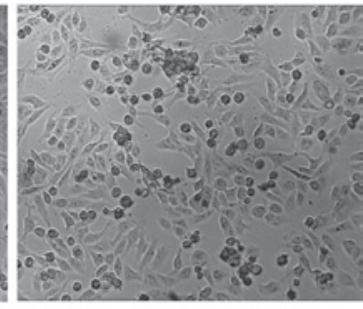

$44^{\circ} \mathrm{C}$
B

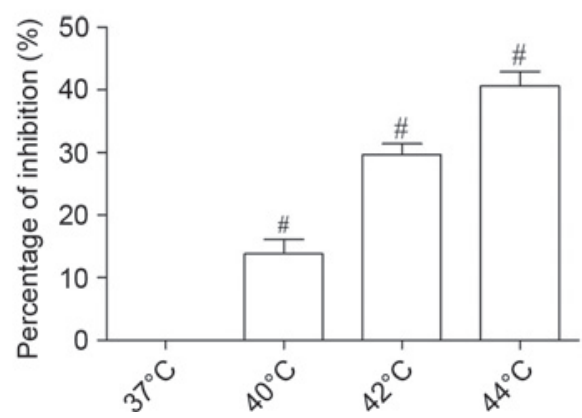

C

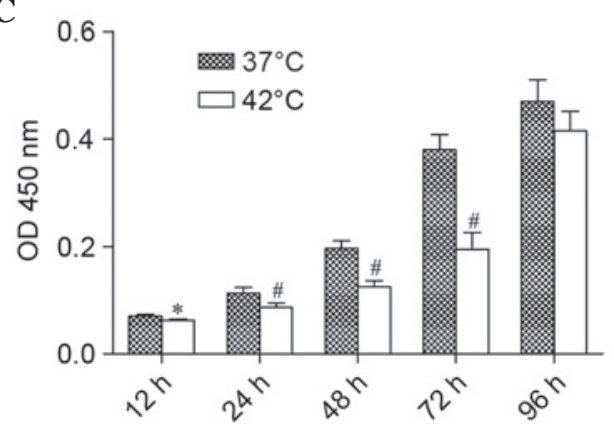

Figure 1. Hyperthermia inhibited the viability of SMMC-7721 cells. The cells were treated with hyperthermia at 40,42 and $44^{\circ} \mathrm{C}$ for 1 h, and cells cultured at $37^{\circ} \mathrm{C}$ were used as the control. (A) Cell morphology following hyperthermia (magnification, x100). (B) Cell viability was determined using a Cell Counting kit-8 assay. (C) Cell growth following hyperthermia at $42^{\circ} \mathrm{C}$ for $1 \mathrm{~h}$. ${ }^{*} \mathrm{P}<0.05,{ }^{\sharp} \mathrm{P}<0.01$, vs. the control cells cultured at $37^{\circ} \mathrm{C}$.

sc-2004; Santa Cruz Biotechnology, Inc., Dallas, TX, USA) at room temperature for $1 \mathrm{~h}$. The immunoreactive bands were detected using an enhanced chemiluminescence kit (PI-32209; Pierce Biotechnology, Inc., Rockford, IL, USA). $\beta$-actin was used as an internal control. The protein concentrations were assessed using a bicinchoninic acid protein assay kit (Beijing Comwin Biotech Co., Ltd.). BCA solution (200 $\mu \mathrm{l})$ was added to each well and allowed to stand at $37^{\circ} \mathrm{C}$ for $30 \mathrm{~min}$. The OD value of each well was read at a wavelength of $562 \mathrm{~nm}$ using a microplate reader (Model 680, Bio-Rad Laboratories Inc.). A standard curve was drawn and the protein concentration was calculated.

Cell proliferation. The CCK-8 kit was used to monitor cell proliferation. Briefly, SMMC-7721 cells were plated at a density of $1 \times 10^{4}$ cells/well in 96-well plates. Three groups were established, including an experimental group (transfection + hyperthermia), a control group (hyperthermia) and a blank control group. In the experimental group, the cells were subjected to heat shock in an incubator at $42^{\circ} \mathrm{C}$ for $1 \mathrm{~h}$ post-transfection. Cells were cultured at $42^{\circ} \mathrm{C}$ for $1 \mathrm{~h}$ without transfection in the hyperthermia group. The blank control group cells were incubated at $37^{\circ} \mathrm{C}$ without any treatment. The absorbance of the cells was determined at a wavelength of $450 \mathrm{~nm}$ according to the manufacturer's protocol. Experiments were conducted in triplicate and the average results were calculated.

Wound-healing assay. SMMC-7721 cells were seeded at an initial density of $5 \times 10^{4}$ cells/well on 24 -well plates and cultured to $80 \%$ confluence. Following treatment, the cells were wounded by manual scraping with a sterile $10-\mu 1$ pipette tip. The culture medium was then replaced with fresh, FBS-free DMEM. Wound closure was monitored at various time points by observation under an inverted microscope, and images were captured at regular time intervals (TE2000-U;
Nikon Corporation). Wound distances were measured at each time point and expressed as the average percentage of wound closure compared with that at $0 \mathrm{~h}$.

Colony forming assay. SMMC-7721 cells were divided into three groups as described above. Cells were collected following hyperthermia treatment and reseeded in 6-well plates $\left(1 \times 10^{3}\right.$ cells/well), each group contained three wells. Following incubation at $37^{\circ} \mathrm{C}$ for 14 days, the cells were washed twice with PBS, fixed with $4 \%$ paraformaldehyde for $15 \mathrm{~min}$ and stained with $2 \mathrm{ml}$ Giemsa reagent for $30 \mathrm{~min}$ (Hematology Laboratory, the Third Affiliated Hospital of Sun Yat-Sen University). The number of colonies containing 50 cells was counted manually under low magnification. Clone formation efficiency was calculated using the following formula: Clone formation efficiency $=$ (number of colonies/number of cells inoculated) $\mathrm{x} 100 \%$.

Flow cytometry. SMMC-7721 cells at an initial density of $5 \times 10^{4}$ cells/well were incubated in 24-well plates and treated as mentioned previously. Cells with different treatments were collected separately and resuspended with PBS. Subsequently, cells $\left(5 \times 10^{5}\right)$ were centrifuged at $500 \mathrm{x} \mathrm{g}$ for $5 \mathrm{~min}$ and the supernatant solutions were discarded. An Annexin V-PE/7-AAD Apoptosis Detection kit (BD Biosciences, Franklin Lakes, NJ, USA) was used according to the manufacturer's protocol. After adding $50 \mu \mathrm{l}$ binding buffer and $5 \mu \mathrm{l}$ 7-AAD, cells were incubated at room temperature for $15 \mathrm{~min}$ in the dark. After that, cells were resuspended with $450 \mu$ l binding buffer and $1 \mu \mathrm{l}$ Annexin V-PE was added. The fluorescence of Annexin V-PE and 7-AAD was measured by flow cytometry (FACSCalibur; BD Biosciences). For cell cycle analysis, cells were collected, washed twice with PBS and incubated with ice-cold $70 \%$ ethanol overnight. Subsequently, the fixed cells were resuspended in PBS and stained with $50 \mu \mathrm{g} / \mathrm{ml}$ prop- 
A

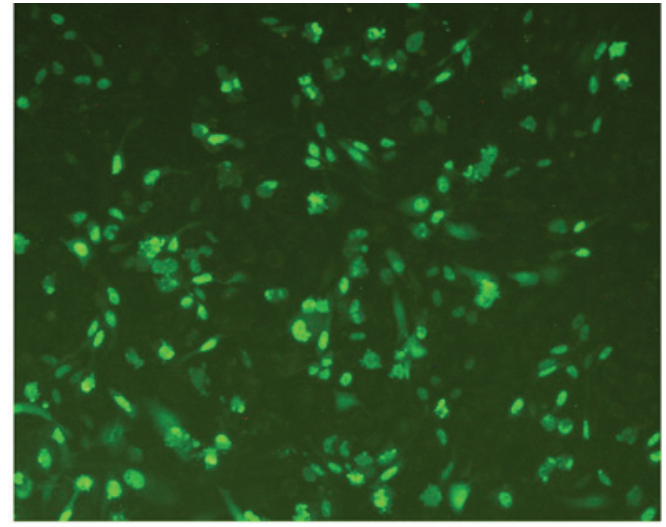

B

mTOR

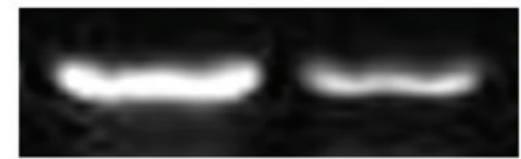

$\beta$-actin

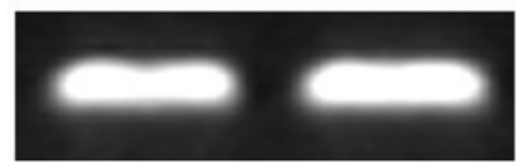

Transfection
$-$

$+$

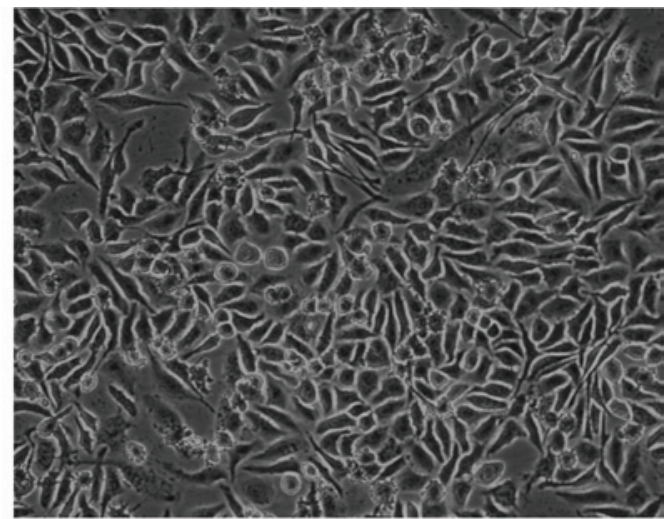

C
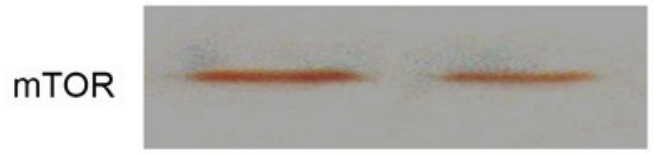

$\beta-a c t i n$

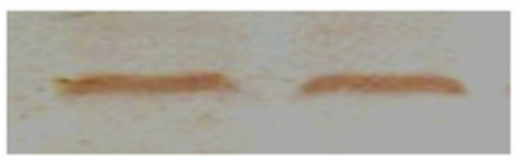

Transfection

$+$

Figure 2. Transfection with pEGFP-C1-mTOR inhibited the expression of mTOR in SMMC-7721 cells. (A) Representative fluorescent micrograph (magnification, x100). (B) The mRNA expression of mTOR as determined by reverse transcription-polymerase chain reaction. (C) mTOR protein expression as determined by western blotting. mTOR, mammalian target of rapamycin.

idium iodide (Sigma-Aldrich) at room temperature in the dark for $30 \mathrm{~min}$. Flow cytometry analysis was performed using the FACSCalibur cytometer.

Statistical analysis. Statistical analysis was performed using SPSS 16.0 software (SPSS, Inc., Chicago, IL, USA). All results were presented as means \pm standard deviation. One-way analysis of variance was used to analyze the statistical differences between multiple groups. $\mathrm{P}<0.05$ was considered to indicate a statistically significant result.

\section{Results}

Hyperthermia inhibits SMMC-7721 cell viability. It has been reported that cancer cells are susceptible to hyperthermia (15). To detect the effects of hyperthermia on SMMC-7721 cells, the cells were exposed to heat treatment at various temperatures. Following hyperthermia, folding of the cell membrane was observed and numerous vacuoles formed in the cytoplasm. As the temperature increased, the number of necrotic cells also increased (Fig. 1A). Hyperthermia significantly inhibited the growth of SMMC-7721 cells compared with cells at $37^{\circ} \mathrm{C}$ $(\mathrm{P}<0.01)$. The inhibitory rate of cells at $44^{\circ} \mathrm{C}$ was increased by $40.65 \%$. Hyperthermia reduced cell proliferation in a temperature-dependent manner (Fig. 1B). SMMC-7721 cell viability was significantly decreased at $42^{\circ} \mathrm{C}$ compared with cells at $37^{\circ} \mathrm{C}$ after $96 \mathrm{~h}$ treatment (Fig. 1C).

Expression of mTOR. Following antisense plasmid pEGFP-C1-mTOR transfection into the SMMC-7721 cells, the expression of green fluorescent protein was observed using

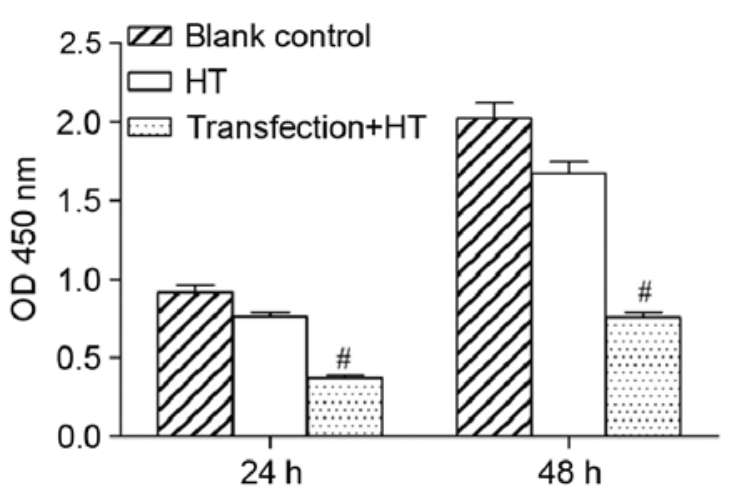

Figure 3. Inhibition of mammalian target of rapamycin increased the effect of HT on cell proliferation. Cells were incubated at $42^{\circ} \mathrm{C}$ for $1 \mathrm{~h}$ post-transfection and cell proliferation was evaluated using a cell counting kit- 8 assay. ${ }^{\#} \mathrm{P}<0.01$ vs. the blank control and HT groups. HT, hypothermia treatment.

inverted fluorescent microscopy (Fig. 2A). The results from the RT-PCR analysis demonstrated that the expression of mTOR mRNA was significantly reduced post-transfection $(\mathrm{P}<0.01)$. The relative values of the two PCR assays were $0.74 \pm 0.04$ and $0.23 \pm 0.01$ (Fig. 2B). The protein expression levels of mTOR were detected using western blotting and demonstrated similar results. The relative values of mTOR protein expression were $0.65 \pm 0.03$ and $0.31 \pm 0.02$, respectively. These results indicated that mTOR protein expression was also significantly decreased post-transfection $(\mathrm{P}<0.05$; Fig. 2C).

Effects of hyperthermia on cell proliferation, colony-forming ability and motility post-transfection. CCK-8 analysis demonstrated a significant reduction in cell viability of the 


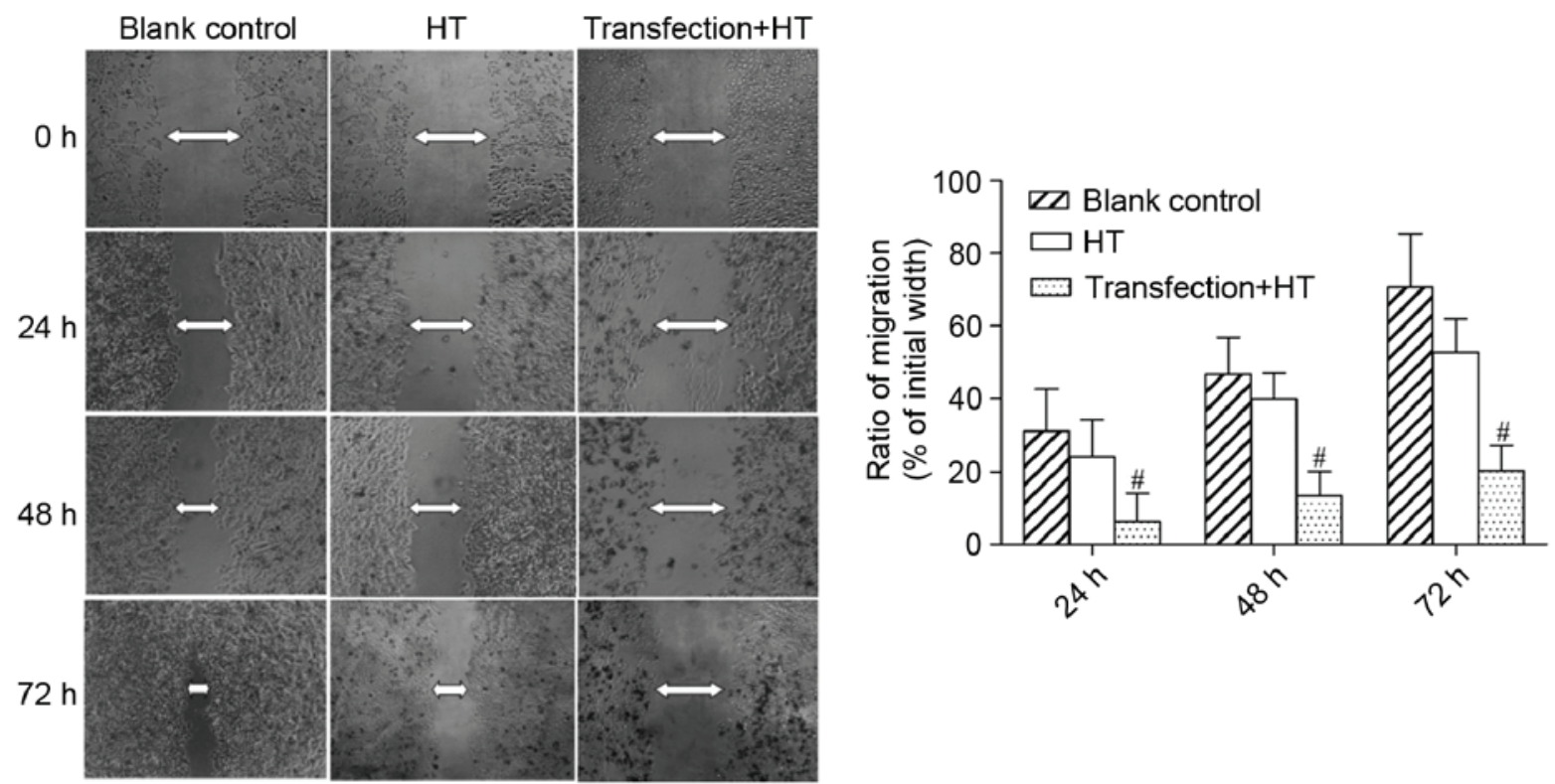

Figure 4. Inhibition of mammalian target of rapamycin increased the effect of HT on cell migration. Cell migration was determined by wound-healing assay. Quantification of cell migration at 24, 48 and $72 \mathrm{~h}$. Mean values from three different experiments are shown. ${ }^{*} \mathrm{P}<0.01$ vs. the blank control and HT groups. HT, hyperthermia treatment.
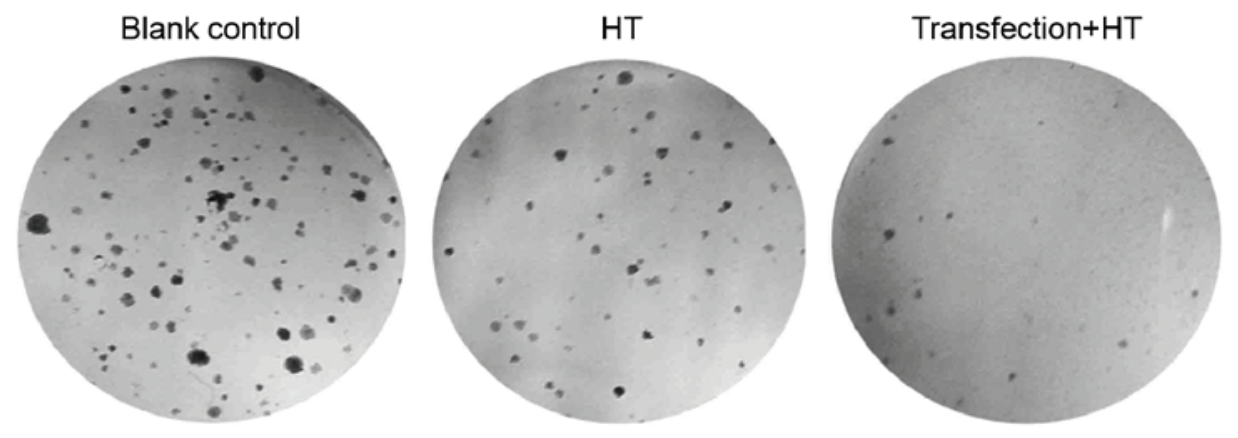

Figure 5. Inhibition of mammalian target of rapamycin increased the effect of hyperthermia treatment on cell colony formation. Colony formation was observed by staining with Giemsa reagent after 14 days.

experimental group at 24 and $48 \mathrm{~h}$ compared with the other groups (Fig. 3). The wound-healing assay demonstrated that numerous cells migrated into the scratch wound area in the control and blank control groups, whereas there were fewer cells in the experimental group (Fig. 4). Furthermore, a larger number of necrotic cells was also observed in the experimental group. These results indicated that cell migration was reduced following treatment. The colony forming assay determined that the clone formation efficiencies for the control and blank control groups were $9.05 \pm 1.97$ and $14.5 \pm 2.45 \%$, respectively. The number of cell colonies was markedly decreased in the experimental group, and the clone formation efficiency was $1.98 \pm 0.61 \%$ (Fig. 5).

Effects of hyperthermia on apoptosis and cell cycle post-transfection. The present study examined whether the change in cell proliferation was associated with the apoptosis induced by heat. As shown in Fig. 6A, the rate of apoptosis for the control and blank control groups was $10.14 \pm 2.66$ and $28.93 \pm 2.51 \%$, respectively. The apoptotic rate in the experimental group was significantly lower compared with that in the other two groups $(52.27 \pm 3.72 \%$; $\mathrm{P}<0.01)$. This result suggests that mTOR expression protects SMMC-7721 cells from heat-induced apoptosis, and thus increases cell survival following exposure to heat. To determine whether the cell cycle was among the mechanisms underlying the change in cell proliferation, flow cytometric analysis was performed. Compared with the other two groups, the number of cells in the $\mathrm{G}_{1}$ phase was decreased in the experimental group. However the proportion of cells in $\mathrm{S}$ phase was increased (Fig. 6B). These results suggest that the transfected cells were arrested in $\mathrm{S}$ phase following hyperthermia.

\section{Discussion}

Hyperthermia has been demonstrated in randomized clinical trials to be an effective treatment strategy in oncology (16). Successful thermotherapies rely on the balance between eliminating cancerous cells and protecting normal cells exposed to high temperatures (17). Hyperthermia leads to cell death depending on the temperature and duration of exposure (3). Tumor heterogeneity may contribute to differences in therapy 

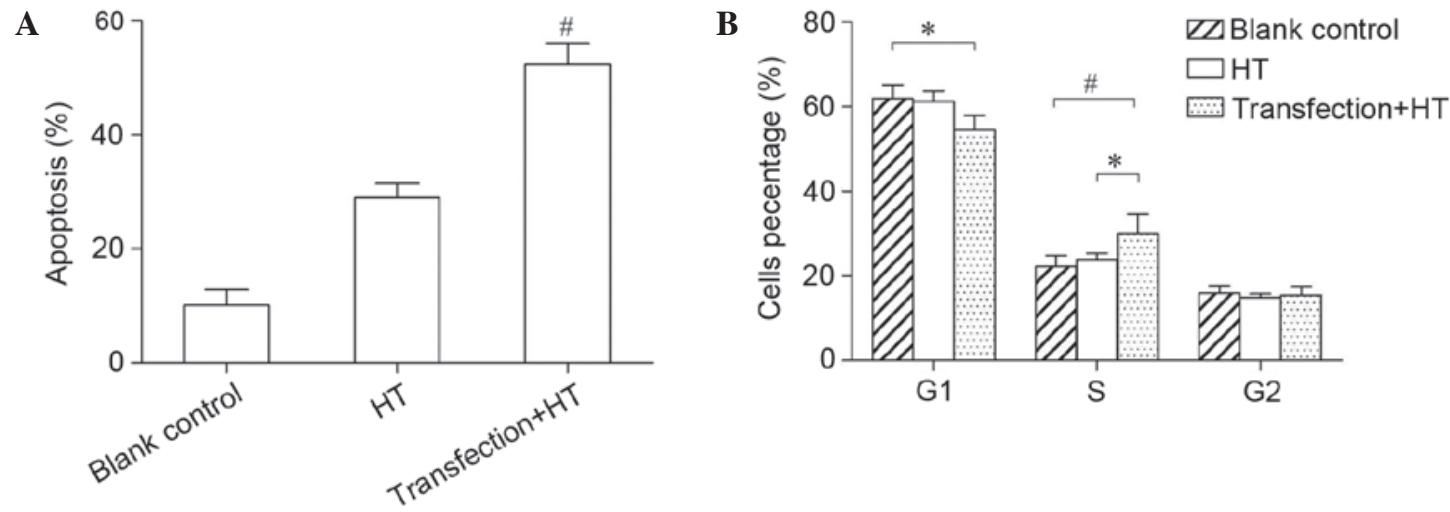

Figure 6. Hyperthermia promoted cell apoptosis and induced S phase cell cycle arrest in SMMC-7721 cells after transfection. (A) The rate of apoptosis, ${ }^{\text {\#}} \mathrm{P}<0.01$, vs the other two groups. (B) Cell cycle analysis, ${ }^{\text {P }}<0.05,{ }^{,} \mathrm{P}<0.01$, compare with blank control or HT group.

response, due to the fact that cell lines exhibit different thermosensitivities (18).

The sensitivity of SMMC-7721 cells to hyperthermia was investigated in the present study. Following hyperthermia at various temperatures, the results demonstrated that SMMC-7721 cells were sensitive to heat treatment. Heat shock destroyed the membranes of the cells and changed the morphology of the cells. Cell proliferation was significantly inhibited following heat treatment. The degree of cell death either by apoptosis or necrosis depends on the tumor cell type and the treatment conditions, with the usual break-point temperature at which cells underwent significant cell death being $42^{\circ} \mathrm{C}$ for $1 \mathrm{~h}$ (3). Therefore, $42^{\circ} \mathrm{C}$ was selected as the temperature to be used in the subsequent experiments, and heat induced a significant growth arrest in the cells within $72 \mathrm{~h}$. The possible mechanisms underlying cell growth arrest may include direct and indirect processes. Direct cytotoxic effects would mean that heat shock destroyed the membrane structure of the tumor cell directly and induced cell apoptosis. In the case of an indirect effect, heat shock would destroy the tumor cell through the induction of reactive oxygen species and free radicals $(19,20)$.

The detailed mechanisms underlying heat induction of cell death remain to be elucidated, although several signaling pathways have been demonstrated to be mediators of this response including the PI3K/Akt/mTOR, mitogen-activated protein kinase (MAPK)/extracellular signal-regulated kinase and p38/MAPK signaling pathways (21). The PI3K/Akt/mTOR pathway is a survival signaling pathway that is constitutively activated in numerous types of cancers (22). mTOR has recently been recognized as potential therapeutic target for cancer therapy (13). The potential applications of mTOR inhibitors for treating various types of cancer, including renal, prostate, breast, pancreatic and lung cancers have been studied preclinically and clinically (23-25).

Therapy resistance is a common clinical problem in HCC. It has been demonstrated that the mTOR signaling pathway is aberrantly activated in HCC (26). Furthermore, activated mTOR confers resistance to numerous types of cancer therapies, and contributes to the observed poor prognosis in HCC (27). The results of the present study were concordant with those of previous studies that reported that inhibition of mTOR may serves as an HCC treatment by enhancing the chemosensitivity of HCC cells $(28,29)$. In addition, inhibition of the mTOR signaling pathway enhanced heat sensitivity in human breast and lung cancers; however, few studies have evaluated heat sensitivity in $\operatorname{HCC}(30,31)$. Following these observations, we aimed to determine whether thermosensitization could be achieved by inhibiting mTOR. The presence of green fluorescent protein in the cells indicated that the antisense pEGFP-C1-mTOR was successfully transfected into the SMMC-7721 cells. The expression levels of mTOR were decreased post-transfection, which made it possible to study the response to thermal treatment in SMMC-7721 cells following knockdown of mTOR expression.

To understand the role of mTOR in modulating cellular responses to thermal stress, transfected SMMC-7721 cells were subjected to heat treatment. The potential antitumoral effect of heat treatment was also investigated in SMMC-7721 cells. A CCK- 8 assay was used to assess cell viability and a colony-forming assay to assess cell proliferation. These assays demonstrated that hyperthermia inhibits the proliferation of SMMC-7721 cells in vitro. In our previous study, it was observed that treatment of cells with antisense pEGFP-C1-mTOR could inhibit the growth of HCC (28). In the present study, the results demonstrated that the inhibitory effects of hyperthermia on the transfected cells was even more significant. The effects of hyperthermia on cell migration were also examined. A previous study showed that mTOR has a critical role in the regulation of tumor cell invasion and cancer metastasis (32). The wound healing assay demonstrated that hyperthermia decreased the ability of SMMC-7721 cells to migrate and repair wounds. In addition, the effect was more apparent when mTOR expression was decreased. These results demonstrated that inhibition of mTOR expression increased the sensitivity of SMMC-7721 cells to hyperthermia.

The results of the Annexin V-PE/7-AAD staining and flow cytometric analyses indicated that the inhibition of mTOR significantly increased the rate of heat-induced apoptosis compared with the controls. This was consistent with the data obtained on the anti-proliferative effects of heat in SMMC-7721 cells and suggested that inhibition of mTOR expression enhanced heat-induced apoptosis.

Finally, the cell cycle was analyzed, and the data indicated that there was no significant difference in the proportion of cells in $G_{2}$ phase. However, the proportion of cells in $G_{1}$ phase 
was reduced, whereas the proportion of cells in $\mathrm{S}$ phase was increased. Therefore, the $\mathrm{S}-\mathrm{to}-\mathrm{G}_{2}$ phase transition was blocked and the cells were arrested in $S$ phase. Hyperthermia usually blocks cells in $\mathrm{G}_{1}$ phase, and few have reported cells blocked in other phases (33). Since DNA synthesis occurs in $\mathrm{S}$ phase and the basic principle of hyperthermia is to change the microenvironment of the cells, the altered microenvironment causes chromosome aberrations and multinucleated cells to form, which may induce apoptosis and necrosis. Furthermore, cells in $\mathrm{S}$ phase are sensitive to heat. The mTOR gene is involved in regulating cyclins $\mathrm{D}_{1} / \mathrm{A}$ and cyclin-dependent kinases (34). It has been reported that $\mathrm{mTOR}$ inhibition induced $\mathrm{G}_{1}$ phase cell cycle arrest (35). Therefore, the interaction between mTOR inhibition and hyperthermia in the cell cycle requires further investigation.

In summary, the present study demonstrated that SMMC-7721 cells were sensitive to heat treatment, and cell viability was significantly inhibited following hyperthermia. Inhibition of mTOR expression increased the thermosensitivity of SMMC-7721 cells by increasing cell apoptosis and $\mathrm{S}$ phase cell cycle arrest. Therefore, mTOR may be involved in mediating heat-induced apoptosis and survival in SMMC-7721 cells. Further understanding of this important signaling pathway may facilitate the development of novel therapeutic strategies to improve the outcomes for patients with HCC. However, the molecular mechanisms underlying mTOR regulation of SMMC-7721 cell response to hyperthermia requires further investigation.

\section{Acknowledgements}

The present study was supported by a grant from the Science and Technology Program of Guangzhou City (grant no. 1563000226).

\section{References}

1. Waly RS, Yangde Z and Yuxiang C: Hepatocellular carcinoma: focus on different aspects of management. ISRN Oncol 2012: 421673, 2012.

2. Yang JD and Roberts LR: Epidemiology and management of hepatocellular carcinoma. Infect Dis Clin North Am 24: 899-919, 2010.

3. Roti Roti JL: Cellular responses to hyperthermia (40-46 degrees C): Cell killing and molecular events. Int J Hyperthermia 24: 3-15, 2008

4. Habash RW, Bansal R, Krewski D and Alhafid HT: Thermal therapy, part 2: hyperthermia techniques. Crit Rev Biomed Eng 34: 491-542, 2006.

5. Mayrhauser U, Stiegler P, Stadlbauer V, Koestenbauer S, Leber B, Konrad K, Iberer F, Portugaller RH and Tscheliessnigg K: Effect of hyperthermia on liver cell lines: Important findings for thermal therapy in hepatocellular carcinoma. Anticancer Res 31: 1583-1588, 2011.

6. Ahmed K and Zaidi SF: Treating cancer with heat: Hyperthermia as promising strategy to enhance apoptosis. J Pak Med Assoc 63 : 504-508, 2013.

7. Jansen MC, van Hillegersberg R, Chamuleau RA, van Delden OM, Gouma DJ and van Gulik TM: Outcome of regional and local ablative therapies for hepatocellular carcinoma: A collective review. Eur J Surg Oncol 31: 331-347, 2005.

8. Decadt B and Siriwardena AK: Radiofrequency ablation of liver tumours: systematic review. Lancet Oncol 5: 550-560, 2004.

9. Griffin RJ, Dings RP, Jamshidi-Parsian A and Song CW: Mild temperature hyperthermia and radiation therapy: Role of tumour vascular thermotolerance and relevant physiological factors. Int J Hyperthermia 26: 256-263, 2010.

10. Sonna LA, Fujita J, Gaffin SL and Lilly CM: Invited review: Effects of heat and cold stress on mammalian gene expression. J Appl Physiol (1985) 92: 1725-1742, 2002.
11. Deng H, Ravikumar TS and Yang WL: Bone morphogenetic protein-4 inhibits heat-induced apoptosis by modulating MAPK pathways in human colon cancer HCT116 cells. Cancer Lett 256: 207-217, 2007.

12. Ma N, Szmitko P, Brade A, Chu I, Lo A, Woodgett J, Klamut H and Liu FF: Kinase-dead PKB gene therapy combined with hyperthermia for human breast cancer. Cancer Gene Ther 11: 52-60, 2004

13. Buitrago-Molina LE and Vogel A: mTor as a potential target for the prevention and treatment of hepatocellular carcinoma. Curr Cancer Drug Targets 12: 1045-1061, 2012.

14. Shaw M, Cohen P and Alessi DR: The activation of protein kinase $\mathrm{B}$ by $\mathrm{H} 2 \mathrm{O} 2$ or heat shock is mediated by phosphoinositide 3-kinase and not by mitogen-activated protein kinase-activated protein kinase-2. Biochem J 336 ( Pt 1): 241-246, 1998.

15. Soares PI, Ferreira IM, Igreja RA, Novo CM and Borges JP: Application of hyperthermia for cancer treatment: recent patents review. Recent Pat Anticancer Drug Discov 7: 64-73, 2012.

16. Kouloulias V, Plataniotis G, Kouvaris J,Dardoufas C, Gennatas C, Uzunoglu N, Papavasiliou C and Vlahos L: Chemoradiotherapy combined with intracavitary hyperthermia for anal cancer: Feasibility and long-term results from a phase II randomized trial. Am J Clin Oncol 28: 91-99, 2005.

17. Palazzi M, Maluta S, Dall'Oglio S and Romano M: The role of hyperthermia in the battle against cancer. Tumori 96: 902-910, 2010.

18. Armour EP, McEachern D, Wang Z, Corry PM and Martinez A: Sensitivity of human cells to mild hyperthermia. Cancer Res 53: 2740-2744, 1993

19. Hildebrandt B, Wust P, Ahlers O, Dieing A, Sreenivasa G, Kerner T, Felix R, and Riess H: The cellular and molecular basis of hyperthermia. Crit Rev Oncol Hematol 43: 33-56, 2002.

20. Wust P, Hildebrandt B, Sreenivasa G, Rau B, Gellermann J, Riess H, Felix R, and Schlag PM: Hyperthermia in combined treatment of cancer. Lancet Oncol 3: 487-497, 2002.

21. Gourgou E, Aggeli IK, Beis I and Gaitanaki C: Hyperthermia-induced Hsp70 and MT20 transcriptional upregulation are mediated by p38-MAPK and JNKs in Mytilus galloprovincialis (Lamarck); a pro-survival response. J Exp Biol 213: 347-357, 2010.

22. Georgakis GV and Younes A: From Rapa Nui to rapamycin: Targeting PI3K/Akt/mTOR for cancer therapy. Expert Rev Anticancer Ther 6: 131-140, 2006

23. Dudkin L, Dilling MB, Cheshire PJ, Harwood FC, Hollingshead M, Arbuck SG, Travis R, Sausville EA and Houghton PJ: Biochemical correlates of mTOR inhibition by the rapamycin ester CCI-779 and tumor growth inhibition. Clin Cancer Res 7: 1758-1764, 2001.

24. Asano T, Yao Y, Zhu J, Li D, Abbruzzese JL and Reddy SA: The rapamycin analog CCI-779 is a potent inhibitor of pancreatic cancer cell proliferation. Biochem Biophys Res Commun 331: 295-302, 2005

25. Atkins MB, Hidalgo M, Stadler WM, Logan TF, Dutcher JP, Hudes GR, Park Y, Liou SH, Marshall B, Boni JP, et al: Randomized phase II study of multiple dose levels of CCI-779, a novel mammalian target of rapamycin kinase inhibitor, in patients with advanced refractory renal cell carcinoma. J Clin Oncol 22: 909-918, 2004.

26. Parent R, Kolippakkam D, Booth G and Beretta L: Mammalian target of rapamycin activation impairs hepatocytic differentiation and targets genes moderating lipid homeostasis and hepatocellular growth. Cancer Res 67: 4337-4345, 2007.

27. Schmitz KJ, Wohlschlaeger J, Lang H, Sotiropoulos GC, Malago M, Steveling K, Reis H, Cicinnati VR, Schmid KW and Baba HA: Activation of the ERK and AKT signalling pathway predicts poor prognosis in hepatocellular carcinoma and ERK activation in cancer tissue is associated with hepatitis $\mathrm{C}$ virus infection. J Hepatol 48: 83-90, 2008.

28. Guo Y, Liang X, Lu M, Weng T, Liu Y and Ye X: Mammalian target of rapamycin as a novel target in the treatment of hepatocellular carcinoma. Hepatogastroenterology 57: 913-918, 2010.

29. Hui IC, Tung EK, Sze KM, Ching YP and Ng IO: Rapamycin and CCI-779 inhibit the mammalian target of rapamycin signalling in hepatocellular carcinoma. Liver Int 30: 65-75, 2010.

30. Ma N, Jin J, Lu F, Woodgett J and Liu FF: The role of protein kinase $\mathrm{B}(\mathrm{PKB})$ in modulating heat sensitivity in a human breast cancer cell line. Int J Radiat Oncol Biol Phys 50: 1041-1050, 2001.

31. Ohnishi K, Yasumoto J, Takahashi A and Ohnishi T: LY294002, an inhibitor of PI-3 K, enhances heat sensitivity independently of p53 status in human lung cancer cells. Int J Oncol 29: 249-253, 2006. 
32. Chin YR and Toker A: Function of Akt/PKB signaling to cell motility, invasion and the tumor stroma in cancer. Cell Signal 21: 470-476, 2009.

33. Zölzer F and Streffer C: Quiescence in S-phase and G1 arrest induced by irradiation and/or hyperthermia in six human tumour cell lines of different p53 status. Int J Radiat Biol 76: $717-725,2000$
34. Ekim B, Magnuson B, Acosta-Jaquez HA, Keller JA, Feener EP and Fingar DC: mTOR kinase domain phosphorylation promotes mTORC1 signaling, cell growth, and cell cycle progression. Mol Cell Biol 31: 2787-2801, 2011.

35. Masuda M,Shimomura M,Kobayashi K, Kojima S and Nakatsura T: Growth inhibition by NVP-BEZ235, a dual PI3K/mTOR inhibitor, in hepatocellular carcinoma cell lines. Oncol Rep 26: 1273-1279, 2011. 